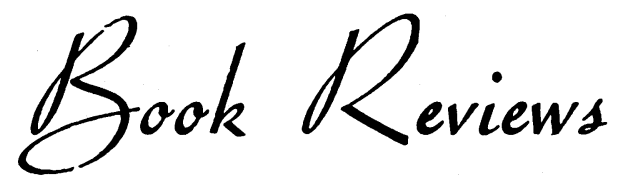

\section{THE CLINICAL APPLICATION OF ANTIBIOTICS \\ Volume 3-Chloramphenicol and the Tetracyclines}

By M. E. Florey, M.D. Pp. 393. London: Oxford University Press. 1957. 84s.

Although this book bears only a single author's name, it is, in fact, the third of a series. The earlier volumes were produced by Sir Howard Florey's team at Oxford and reported much of their own experience as well as a review of the literature. In this volume Lady Florey emphasizes other people's work. This does not make the book any the less welcome. Until now we have been mainly dependent on the American reviews to fill the gaps left by earlier volumes; gaps due, of course, to the date of publication, which necessarily precluded any serious discussion of the more recent drugs. Compared with other reviews, it is a relief to find that the trivial articles and observations have been reduced to their proper place and credit given largely to the source papers and original investigations. The defects are unimportant. In the actual copy reviewed a whole page is given to corrections of the discrepancies between text and bibliography. Many of the errors are merely in the spelling of names and will hardly cause inconvenience. Unfortunately, there are still a few references in the text which cannot be traced in the list provided. It is to be hoped that in later impressions these blemishes will be removed from a book which will take its place beside the earlier volumes as the major British reference book in this field.

\section{W.H.H.}

\section{FUNDAMENTALS OF IMMUNOLOGY}

By William C. Boyd. Third edition. Pp. xiv + 776 , illustrated. London and New York: Interscience Publishers Inc. 1956. \$10.00.

It is impracticable to attempt a detailed review of this third edition of a standard book. The earlier material has been revised and brought up to date. The bench worker will find the details of the standard technical procedures, including the methods for the statistical analysis of results, helpful and reasonably accurate. The main body of the book covers more than is needed by the medical student and will serve as a reference book for any but the specialist in immunology. Specialists in every field will claim that the space given to their interests is inadequate and the conclusions superficial. The section on clinical allergy, for example, minimizes both diagnostic and immunological difficulties and naively suggests that avoidance is the first choice in treatment, without pointing out that whole groups of offending substances such as aniline dyes are omnipresent in a civilized community. This type of criticism is evidence that this book is well suited to the needs of the average reader and is fairly balanced. It can be wholeheartedly recommended to anyone interested in getting an overall picture of the present knowledge of theoretical and applied immunology.

W.H.H.

TEXTBOOK OF ORTHOPAEDIC MEDICINE Volume I-Diagnosis of Soft Tissue Lesions By James Cyriax, M.D., M.R.C.P. Third edition. Pp. xiv +711 , with 131 diagrams. London: Cassell \& Co. Ltd. 1957. 45 s.

The new edition of this well-known book is substantially unchanged. There are some additions, which increase its value, such as the summary of criteria of reducibility of cervical disc lesions, a section on the sternoclaviculae joints and one on the ischaemic pain produced by tight fascia of the anterior compartment of the leg.

This book has a wide appeal to members of the medical profession and to physiotherapists and has made a large contribution to the solution of problems posed by skeletal pain.

\section{SIMULIUM AND ONCHOCERCIASIS IN THE NORTHERN TERRITORIES OF THE GOLD COAST}

By G. CrisP, B.Sc., Ph.D., F.Z.S., F.R.E.S. Pp. $\mathrm{xvi}+\mathrm{I} 7 \mathrm{I}$, with 5 maps and 54 illustrations. London: H. K. Lewis \& Co. Ltd. 1956. 57s. 6d.

This is an entomological survey of onchocerciasis as it affects the Northern Territories of the Gold Coast. The Onchocerca is a parasitic worm of the filaria group and the disease is transmitted to man by the Simulium damnosum fly; the commonest lesions are cutaneous and the most usual serious ones are ophthalmic. It is estimated that of the one million Africans living in the area covered by 